\title{
Validation of airborne and satellite altimetry data by Arctic Trucks citizen science
}

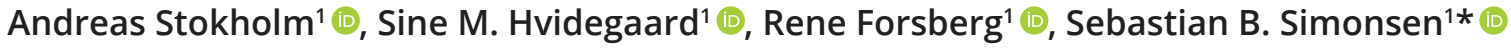 \\ 'DTU Space, National Space Institute, Technical University of Denmark, Lyngby, Denmark
}

\begin{abstract}
The elevation of ice sheets changes due to climate change, and satellite altimetry is the preferred tool for measuring ice sheet-wide height changes. In situ validation is needed to ensure the quality of the observed elevation changes, but the cost often limits the amount of in situ data which can be collected. As more tourists are accessing the ice sheets, citizen science might provide in situ data in an environmentally friendly and cost-efficient way. Here, we investigate the opportunistic kinematic global positioning system (GPS) profiles across the Greenland ice sheet, collected by the American-Icelandic expedition on the Greenlandic icecap 2018. The collected GPS data are in good agreement with the widely used NASA's Operation IceBridge Airborne LiDAR data measured within \pm 10 days, with an average difference of $10.7 \mathrm{~cm} \pm 11.7 \mathrm{~cm}$. The main difference is attributed to changes in the compaction of the snow while driving and changes in the tires' pressure. The kinematic GPS data are then compared with data from the European Space Agency's CryoSat-2 mission. Here, an average bias of $92.3 \mathrm{~cm} \pm 65.7 \mathrm{~cm}$ in the two records is observed between the spring CryoSat- 2 and the truck GPS data obtained largely in the dry-snow zone. This suggests that the surface penetration of Ku-band radar on the Greenland ice sheet and the observed magnitude are consistent with the literature. Finally, we compared the 2018 GPS data to a profile obtained in 2005 near Kangerlussuaq, West Greenland. Here, the records show an average ice-elevation decrease of $9 \mathrm{~m}$, with peaks at $26 \mathrm{~m}$. These results show that the citizen science kinematic GPS data can provide high-resolution data necessary for the validation of satellite altimetry, with the added benefit of potential direct sampling properties of the surface and firn. Linking up with citizen-science expeditions is a beneficial way of providing cost-effective satellite validations and may also have a societal impact by involving more people in the climate monitoring of ice sheets.
\end{abstract}

\section{Introduction}

The launch of the European Space Agency's (ESA's) first European remote sensing satellite (ERS-1) in 1991 made the Greenland ice-sheet-wide monitoring of the surface-elevation change possible. Since then, satellite altimeters have provided an unbroken record of changes in ice-sheet surface elevation (Forsberg et al. 2017; Shepherd et al. 2018 Sørensen et al. 2018a). This 30-year record from ERS-1, ERS-2, Envisat, ICESat, CryoSat-2, and the latest ICESat-2 satellites will continue into the future with the commissioning of the Sentinel-3 satellite series by the European Commission (Seitz et al. 2010). This record has proven

\author{
*Correspondence: ssim@space.dtu.dk \\ Received: 02 Jun 2020 \\ Accepted: 16 Mar 2021 \\ Published: 28 May 2021
}

Keywords: satellite validation, altimetry, CryoSat-2, Operation IceBridge, citizen science

\author{
Abbreviations: \\ ALS: Airborne LiDAR scanning \\ ATM: Airborne topographic mapper \\ CryoVEx: CryoSat-2 validation experiment \\ DEM: Digital elevation model \\ DTU Space: National Space Institute, \\ Technical University of Denmark \\ ESA: European Space Agency \\ GIMP: Greenland Ice Mapping Project \\ GNSS: Global navigation satellite system \\ GrIS: Greenland ice sheet \\ LRM: Low resolution mode \\ PARCA: Program for Arctic Regional Climate \\ Assessment \\ PPP: Precise point positioning \\ PROMICE: Programme for Monitoring of \\ the Greenland Ice Sheet \\ RMSE: Root mean square error \\ RTK: Real-time kinematic \\ SARIn and SIN: SAR interferometric mode \\ SIRAL: Synthetic aperture radar (SAR) \\ interferometric radar altimeter.
}

GEUS Bulletin is an open access, peerreviewed journal published by the Geological Survey of Denmark and Greenland (GEUS). This article is distributed under a CC-BY 4.0 licence, permitting free redistribution, and reproduction for any purpose, even commercial, provided proper citation of the original work. Author(s) retain copyright.

Edited by: Signe Hillerup Larsen (GEUS, Denmark)

Reviewed by: Laurence Gray (University of Ottawa, Canada) and one anonymous reviewer.

Funding: None declared

Competing interests: None declared

Additional files: None provided 
more valuable as societal interest in climate change has increased, including the rapid changes of the marginal zones of the Greenland ice sheet (Khan et al. 2015).

With the growing interest in ice-sheet responses to climate change, validation efforts have become increasingly in demand, and we need to explore new ways to acquire validation data. In the past, the preferred source of validation data for satellite altimetry has been airborne LiDAR scanning (ALS). These ALS measurements started in Greenland with the airborne topographic mapper (ATM) instrument in 1993; then, they were a part of the NASA's Program for Arctic Regional Climate Assessment (PARCA) programme (Krabill et al. 2000) and continued under Operation IceBridge from 2009 (Studinger et al. 2010) to 2019. In addition, the National Survey and Cadastre (later DTU Space) has operated airborne laser scanners in Greenland since 2000. This was done in support of, for example, the Programme for Monitoring of the Greenland Ice Sheet (PROMICE) in 2007, 2011 and 2015 (Ahlstrøm et al. 2008; Fausto et al. 2012); airborne gravity missions from 2001 to 2003; and numerous ESA CryoSat-2 Validation Experiment (CryoVEx) campaigns since 2003 (Skourup et al. 2012, 2013). As airborne validation efforts are costly, here we present a cost-efficient alternative for the purpose of satellite validation, whereby citizen scientists collect kinematic global positioning system (GPS) profiles from opportunistic ground traverses on the ice sheet.

The Icelandic company Arctic Trucks has demonstrated a unique ability to drive long traverses in Antarctica, especially in East Antarctica, but also crossing the Antarctic Plateau from the Union Glacier to the Amundsen Coast in West Antarctica. In Greenland, the ground covered is more limited, with shorter traverses in southern Greenland in the 2005, mainly to support the temporary Volkswagen winter-test site on the ice sheet near Kangerlussuaq. Returning to Greenland in 2018, Arctic Trucks completed their first north-south traverse of the Greenland ice sheet during the American-Icelandic expedition on the Greenlandic icecap 2018. The expedition used three modified fourwheel drive trucks (Fig. 1C) and seven crew members to demonstrate their capabilities in Greenland. The traverse started near Isortoq on 19 April 2018 in southern Greenland and reached land in northernmost Greenland on 29 April 2018 at Wulff Land. Then, it returned south before again exiting the Greenland ice sheet on 7 May 2018 near Kangerlussuaq, from which the trucks drove over an additional $180 \mathrm{~km}$ of ice-free terrain to ship the trucks back to Iceland from the coastal town of Sisimiut. At the end of the 19-day traverse (8 May 2018), more than $5000 \mathrm{~km}$ of inaccessible terrain had been driven (Fig. 1A). We used this opportunity to supply the expedition with a geodetic GPS receiver in hopes of collecting the valuable ground-truth data of ice-sheet elevation along the track.
Here, we evaluated the accuracy of the gathered GPS measurements and assessed their suitability for providing cost-efficient data to validate satellite altimetry. Firstly, we assessed the acquired data in relation to the traditional airborne ALS data gathered by Operation IceBridge. After this, we performed an inter-comparison to CryoSat-2 satellite data. Finally, we showed the long-term capabilities of geodetic GPS measurements, by assessing the elevation change near Kangerlussuaq between the first measurements in 2005 (i.e. the IceRoad route; Fig. 1D) and the 2018 Arctic Truck traverse.

\section{Data and methods}

\subsection{Arctic Trucks kinematic GPS measurements} A portable geodetic Javad TRE-3N Delta Global Navigation Satellite System (GNSS) receiver was mounted on top of one of the Arctic Trucks vehicles (Fig. 1C). The GPS continuously logged the position and elevation of the truck at an interval of $2 \mathrm{sec}$. All GPS data were processed with NovAtel's WayPoint Product Group post-processing product GrafNav in precise point positioning (PPP) mode. This method of GNSS processing uses precise orbit and clock information to provide the state-of-the-art positioning for remote locations without base stations or online corrections (from, e.g., Real-time kinematic [RTK] services), with a typical accuracy of $5 \mathrm{~cm}$ for airborne applications, as demonstrated by, for example, the DTU Space CryoVex campaigns (Skourup et al. 2012, 2013). To link the GPS antenna position to the snow surface, the Arctic Trucks crew repeatedly measured the distance from the snow surface to the antenna reference level, following the tire pressure changes. The values ranged between $227 \mathrm{~cm}$ and 243 $\mathrm{cm}$ and have been corrected for. The measurements were taken while the truck was stationary, giving rise to further submergence into the snow compared to when the truck was being driven. Consequently, kinematic measurements will have a small positive error. Additional uncertainties include the varying weight (e.g. consumables such as fuel) of the vehicle further changing submergence, uneven surfaces and the suspension while driving. However, none of these uncertainties were investigated further.

Unfortunately, no GPS data were collected for 6 days during the crossing from Wulff Land south (31 April-5 May), and the GPS data are only available from 19 to 30 April and again from 6 to 8 May 2018. This results in only limited crossover points for the internal validation of the data collected by the GPS receiver. The crossover location is seen in Fig. 1A, and here, the performance of the geodetic GPS is validated to check for significant snow deviations and/or faulty equipment. The crossover samples occur at very close proximity, with many measurements within metres of the ascending track on 21 and 22 April and the descending track on 6 May, which allow for a precise GPS height comparison. Using the nearest 


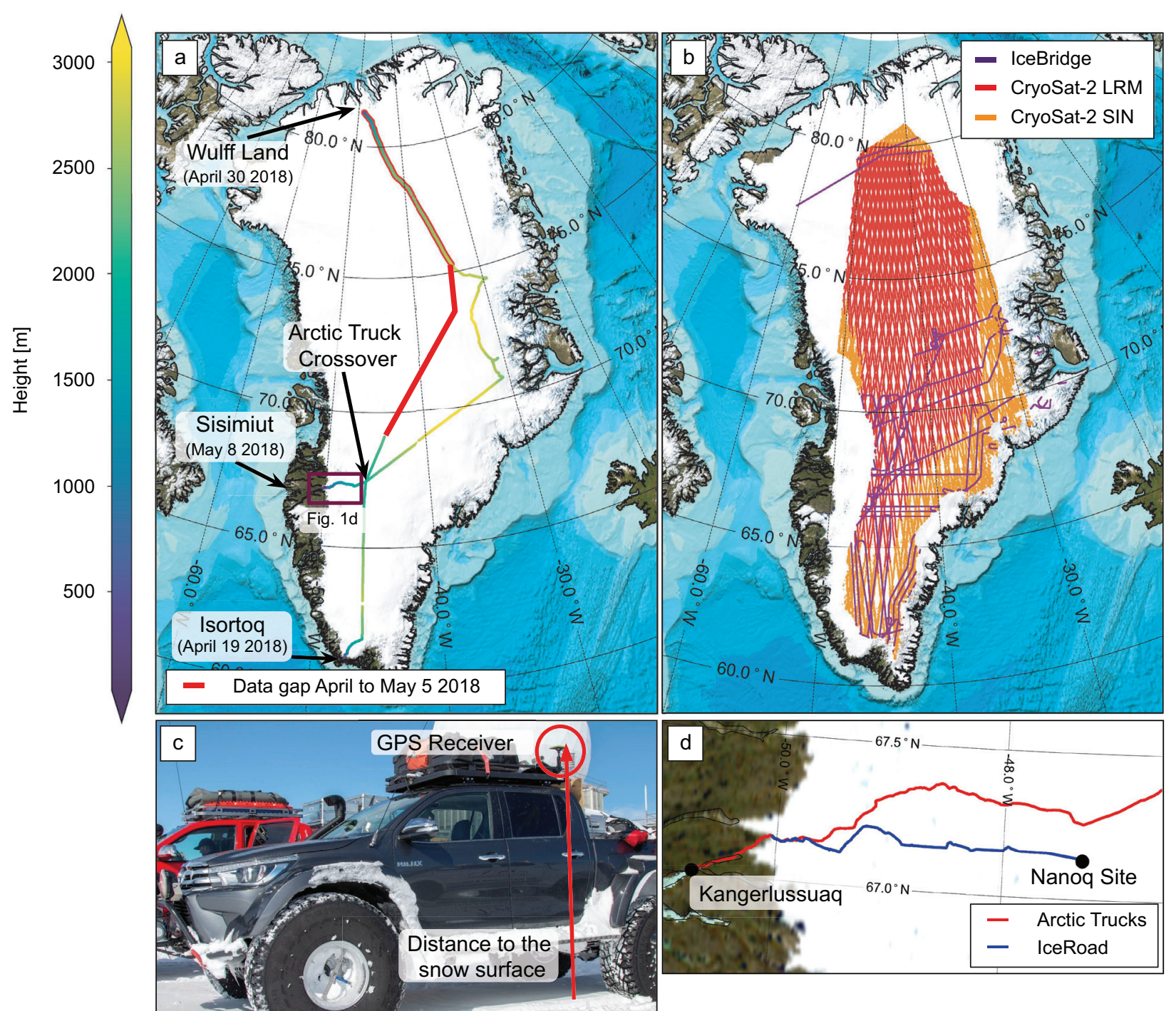

Fig. 1 Map of the expedition route including places visited and dates. a: Height data from the geodetic GPS mounted on the Arctic Trucks. b: Operation IceBridge and CryoSat-2 data coverage at elevations above $2000 \mathrm{~m}$ across Greenland. CryoSat-2 data are only shown between 30W and 50W. c: The modified four-wheel drive Toyota vehicles used on the Arctic Trucks expedition. The GPS receiver is circled in red (Picture courtesy of Emil Grimsson, Arctic Trucks, Iceland). d: Comparison of the 2018 Arctic Trucks and 2005 IceRoad routes. Images reproduced from the GEBCO world map 2014 (www.gebco.net.)

neighbour algorithm with a relatively short Euclidean distance of $10 \mathrm{~m}$ generates a height difference average of $-2.2 \mathrm{~cm}$ with a root mean square error (RMSE) value of $2.6 \mathrm{~cm}$ by comparing 844 crossover points (Table 1 ). Consequently, it is assumed that there has been no significant snow elevation change over the survey period and that the GPS measurements are accurate to a few centimetres RMSE. The spring period of April and May was chosen for the traverse as it offers relatively warm weather, sunlight and stable ice bridges over the crevasses, which are to be crossed when entering and exiting the Greenland ice sheet.

\subsection{Operation IceBridge ATM data}

Operation IceBridge was a NASA programme (2009-2019) that collected airborne remote sensing measurements and incorporated multiple instruments to map ice-surface topography. Here, we apply data from the ATM instrument package, which includes ALS, GPS and inertial navigation systems. The ATM-L2-data (Studinger 2018) are a sequence of laser footprints with a size of c. $1 \mathrm{~m}$ measured in a circular motion in a swath ranging from $400 \mathrm{~m}$ to $1200 \mathrm{~m}$ depending on the aircraft height (typically 500-1500 m) and the incidence angle. The NASA ATM Level 2 Elevation, Slope, and Roughness software condenses the ATM point measurements by fitting a plane to blocks of points at regular intervals with $50 \%$ overlap. Along-track spacing is typically $30 \mathrm{~m}$ but is dependent on the aircraft speed. For each alongtrack position, 3-5 evenly spaced across-track points are sampled for either the T2 or T3 ATM scanner. Each point typically covers $133 \mathrm{~m}$ across track when the swath is 
Table 1 Statistics for the Arctic Trucks kinematic GPS data (572 607 observations) compared with Operation IceBridge, CrysSat-2 and IceRoad data.

\begin{tabular}{|c|c|c|c|c|c|c|c|c|}
\hline & $n$ & Mean $[\mathrm{m}]$ & Med. [m] & Std $[\mathrm{m}]$ & $\operatorname{Max}[\mathrm{m}]$ & $\operatorname{Min}[\mathrm{m}]$ & RMSE [m] & $\mathrm{D}[\mathrm{m}]$ \\
\hline$\overline{\text { GPS validation }}$ & 844 & -0.022 & -0.021 & 0.015 & 0.057 & -0.072 & 0.026 & 10 \\
\hline$\Delta \mathrm{H}_{\mathrm{OIB}}$ & 1217 & -0.107 & -0.110 & 0.117 & 0.280 & -0.648 & 0.159 & 75 \\
\hline$\Delta \mathrm{H}_{\mathrm{CS} 2}$ & 10463 & 0.923 & 0.905 & 0.657 & 5.619 & -5.631 & 6.764 & 75 \\
\hline$\Delta \mathrm{HIR}_{\text {Edge }}$ & 104 & -16.995 & -16.385 & 3.842 & -9.644 & -26.042 & 16.158 & 75 \\
\hline$\Delta \mathrm{HIR}_{\text {Interior }}$ & 277 & -9.035 & -9.713 & 6.940 & 9.900 & -25.929 & 11.392 & - \\
\hline
\end{tabular}

$n$ denotes the number of points in the derived statistics (Mean, Med.: median; std.: standard deviation). RMSE: root mean square error. $D$ denotes the distance used in the nearest neighbour algorithm. CryoSat-2 outliers larger than 3 standard deviations have been removed. OIB: Operation IceBridge; CS2: CryoSat-2; IR: IceRoad.

$400 \mathrm{~m}$ across and $45 \mathrm{~m}$ along track. An additional block is measured at the nadir with an across-track length of $80 \mathrm{~m}$ and a similar along-track width for a total of 4 or 6 blocks. The vertical accuracy and precision of the ATM instrument package are $6.6 \mathrm{~cm}$ and $3 \mathrm{~cm}$, respectively (Martin et al. 2012).

For this study, we selected ATM data coinciding within 10 days of the 2018 Arctic Trucks traverse GPS observation (Fig. 1B) measured at altitudes above 2000 $\mathrm{m}$ where the ice sheet is most level. This ensures limited weather-induced changes in the snowpack between the two types of observations and minimises the potential effects of the surface slope.

Crossovers between Operation IceBridge and Arctic Trucks are found by applying a nearest neighbour algorithm, locating all Operation IceBridge values within a selected Euclidean distance of the Arctic Trucks points.

To limit the potential elevation deviation from terrain slopes, both Operation IceBridge and Arctic Trucks data are subtracted from a digital elevation model (DEM) using the Greenland Ice Mapping Project (GIMP) DEM (Howat et al. 2014) and bilinear interpolation. The GIMP DEM from 2007 has a spatial resolution of $30 \mathrm{~m}$ with an error ranging from $\pm 1 \mathrm{~m}$ on the Greenland ice sheet to $\pm 30 \mathrm{~m}$ in areas with high relief (Howat et al. 2014). The final crossover values are found as the average of these neighbours for each point:

$$
H_{O I B}=\frac{1}{N_{N N}} \cdot \sum_{n=1}^{N_{N N}} H_{n}-D E M
$$

where $H_{n}$ is the elevation of the Operation IceBridge neighbours, $H_{O I B}$ is the crossover elevation of Operation IceBridge and $N_{N N}$ is the numbers of nearby neighbours. We define the measurement accuracy as:

$$
\Delta H_{O I B}=\left(H_{A T}-D E M\right)-\left(H_{O I B}\right)
$$

where $H_{A T}$ is the elevation of the Arctic Trucks measurements with the DEM subtracted. The Operation
IceBridge measurements are in general located further away from the Arctic Trucks track. To ensure sufficient measurements, a higher Euclidean distance for the nearest neighbour algorithm is necessary. In fact, the error, $\Delta H_{O I B^{\prime}}$ scales as a Fermi Dirac-like function of the distance, and using the relative optimum of $75 \mathrm{~m}$ ensures that most data have a minimal $\Delta H_{O I B}$. Increasing the distance will enlarge $\Delta H_{O I B}$ as more points further away from the track are included, introducing surface elevation changes. We then defined the Arctic Trucks measurement accuracy $\left(\varepsilon_{A T}\right)$ as the average of all $\Delta H_{O I B}$. $\varepsilon_{A T}$, which incorporates the uncertainties associated with driving, local terrain variations and GPS inaccuracies.

\subsection{CryoSat-2 - Satellite data}

ESA's CryoSat-2 satellite was launched on 8 April 2010 into a full repeat of its orbit in 369 days and with a sub-cycle of 30 days. The main instrument onboard the satellite is the synthetic aperture radar (SAR)/Interferometric Radar ALtimeter (SIRAL). For the area of Greenland, the SIRAL instrument operates in two modes: (1) In the interior parts of the ice sheets, it operates in the low-resolution mode (LRM), which is equivalent to the conventional beam-limited mode applied by previous Ku-band radar altimeters; (2) Over the coastal areas, SIRAL is switched into the SAR interferometric (SARIn or SIN) mode, in which the dual antennas provide a directionally determined radar return across-track and a high-resolution synthetic aperture processing along-track (Bouzinac 2012). We use both LRM and SIN mode as processed in the official ESA level 2 processing-chain baseline CACS Team \& MSSL Team. (2015). The pulse-limited footprint of CryoSat-2 in LRM mode is about $2.15 \mathrm{~km}^{2}$, with a width of 1.65 km (Bouzinac 2012). Further, we limit the CryoSat-2 data from 9 April to 18 May 2018 (Fig. 1B), corresponding to the timing of the Arctic Trucks traverse of \pm 10 days. Similar to Operation IceBridge, the data are limited to elevations above $2000 \mathrm{~m}$.

With the estimate of $\varepsilon_{A T}$ from the Operation IceBridge analysis, Arctic Trucks GPS data can be compared to CryoSat-2, and crossovers are found in a similar fashion 
to the Operation IceBridge study, by subtracting the 2007 GIMP DEM and applying the nearest neighbour algorithm with a Euclidean distance of $75 \mathrm{~m}$. Using a lower Euclidean distance, for example, 50 m, decreases the amount of available crossover points by $94 \%$. Afterward, CryoSat-2 (CS2) is validated by calculating the height difference:

$$
\Delta H_{C S 2}=\left(H_{A T}-D E M\right)-\left(H_{C S 2}\right)
$$

\subsection{The 2005 IceRoad data}

The IceRoad data were collected in May 2005 on another opportunity truck traverse, as the Volkswagen winter-test site on the ice sheet was closing down. The GPS profile was measured along the IceRoad from point 66 at the ice-sheet margin near Kangerlussuaq to the Volkswagen winter-test site location, called Nanoq (Fig. 1D). An Ashtech Z-12 mobile receiver with a sampling interval of 5 sec was used and mounted on top of the vehicle, similar to Arctic Trucks, with a measured height of 2.45 $\mathrm{m}$, which has been corrected for. The compacted ice road was slightly elevated in comparison to the surrounding snow surface. The GPS data have been post-processed using precise orbit and clock information (Waypoint software in PPP mode). The formal uncertainty estimate from this processing is $0.3 \mathrm{~cm}$, but the absolute vertical accuracy of GPS solutions in kinematic mode is often found to be around 5-10 cm under Arctic conditions (Sørensen et al. 2018b). After reprocessing, it became obvious that the 2005 and 2018 traverses intersect for about $300 \mathrm{~km}$, in the ablation zone of the Greenland ice sheet near Kangerlussuaq (Fig. 1D).

Here, we compared the 2005 IceRoad and 2018 Arctic Trucks traverses in two steps. The overlapping region illustrated in Fig. 1D is found using the nearest neighbour algorithm with a distance of $75 \mathrm{~m}$, which seems to be a good fit between the spatial proximity and elevation difference. Further inland, the two truck routes diverge and are separated by kilometres in latitude, and therefore, the crossovers method is not appropriate. Instead, both tracks are compressed into blocks based on the overlapping longitude as the traverse is largely from east to west. Each block incorporates all points with a $100 \mathrm{~m}$ interval in longitude yielding 277 blocks where the longitude, latitude and elevation have been averaged into one point. Afterward, the slope-dependent elevation is removed by correcting the DEM differences for both the IceRoad (IR, in equation 4) and the Arctic Trucks data with the GIMP DEM. Thereby, the elevation changes from 2005 to 2018 are estimated for the interior portion of the overlapping tracks:

$$
\Delta H_{I R_{\text {interior }}}=\left(H_{I R}-D E M\right)-\left(H_{A T}-D E M\right)
$$

\section{Results}

The distribution of all validation targets is shown in Fig. 2, and the accompanying statistics are listed in Table 1, in which we include the number of samples, mean, median, standard variance, max., min., RMSE and the Euclidean distance in the nearest neighbour algorithm. These statistics are based on the data illustrated in Fig. 1.

From the statistics of the different inter-comparisons given in Table 1, it is evident that $\Delta H_{O B B}$ has fewer data points than CryoSat- 2 despite having a much higher sampling frequency. This is partly because most of the Operation IceBridge data are near the coast (typical for their acquisitions and flying tracks), leaving few overlapping areas with Arctic Trucks, while CryoSat- 2 has a larger coverage. We find that the elevations measured with Operation IceBridge and Arctic Trucks are mostly similar, with relatively small outliers, while in comparison, CryoSat-2
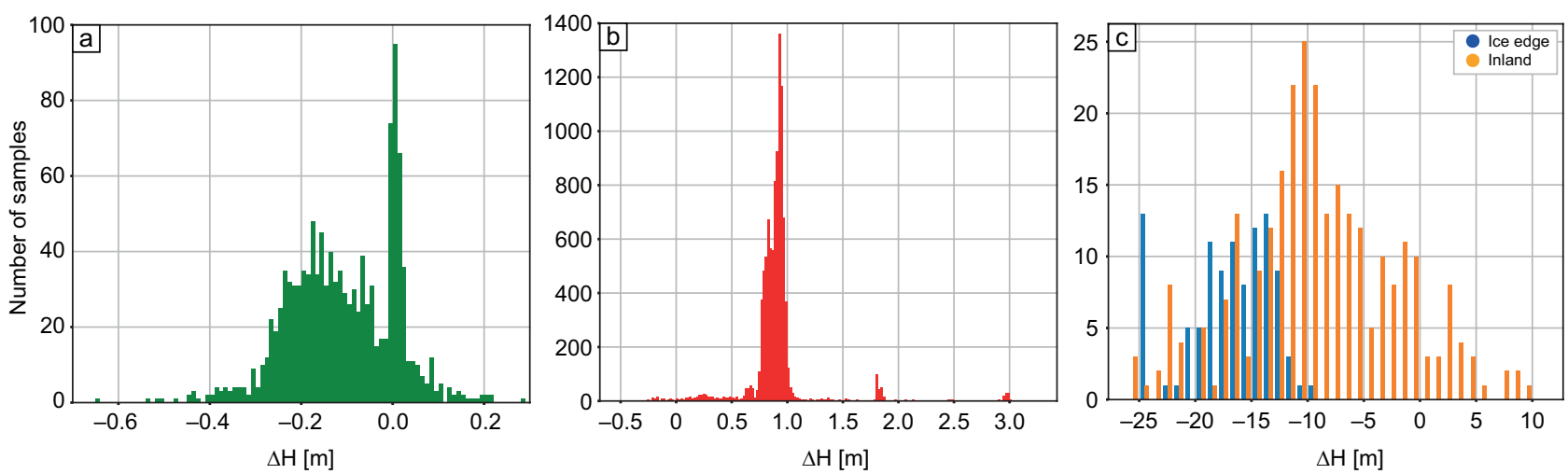

Fig. 2 Histograms of the elevation differences $(H)$ between the Arctic Truck acquisition and data from a: Operation IceBridge $H_{O / B}$ has a bin size of $1 \mathrm{~cm}$ and there are no significant data clusters outside the range -0.7 to $0.3 \mathrm{~m}$, b: CryoSat- $2 \mathrm{H}_{c S 2}$ has a $2 \mathrm{~cm}$ bin size, with no significant clusters outside -0.5 to $3.25 \mathrm{~m}$, c: IceRoad $H_{I R}$ in the range of -26 to $12 \mathrm{~m}$ with a bin size of $1 \mathrm{~m}$; no data occur outside of this range. 
has large outliers, despite removing outliers \pm 3 standard deviations from $\Delta H_{C S 2}$. Similar means and medians indicate that most overlapping data points are relatively close to the $\Delta H$ for both Operation IceBridge and CryoSat-2. Based on the average $\Delta H$, we see that Operation IceBridge generally measures a higher elevation and CryoSat-2 measures a lower elevation compared to Arctic Trucks. The average of $\Delta H_{O I B}$ is $10.7 \mathrm{~cm}$, and the histogram in Fig. 2A illustrates that nearly all data points are located in the range of -30 to $10 \mathrm{~cm}$, with a wide and tall cluster. The mean and median of Operation IceBridge are very similar, indicating that the mean is not significantly affected by large outliers. The CryoSat- 2 histogram contains a main cluster from 60 to $105 \mathrm{~cm}$ region with two small clusters at $175-190 \mathrm{~cm}$ and at $290-305 \mathrm{~cm}$. If the large outliers were not removed from the CryoSat-2 data, the mean would be significantly altered.

The elevation differences for the IceRoad data (Fig. 2C) show a different distribution for measurements near the ice sheet edge compared to the interior measurements. The spread at the ice edge is attributed to the non-uniform elevation change in this part of the ice sheet, whereas the larger spread in the interior observations can be attributed to the divergence of the two traverse routes.

\section{Discussion}

Operation IceBridge ATM data have been used to assess the performance of the Arctic Trucks GPS observations of the ice-sheet surface elevation, and the results show an average difference of $10.7 \mathrm{~cm} \pm 11.7 \mathrm{~cm}$. The bias is likely from a combination of Arctic Trucks uncertainties, the uncertainties from the ATM data and the footprint coverage of the ATM ICESSN point compression. Regarding the Arctic Trucks measurements, we note that the main uncertainties are the tendency of the wheels to compress the uppermost snow layer, the uneven surfaces and some counteraction of the vehicle suspension system while driving. The tire pressure is generally low to provide a larger surface grip, and it is adapted to snow conditions as necessary (low for soft snow and high for solid surfaces). Regarding the submergence into the snow, we argue that the mean error is not zero, because the height measurement of the elevated GPS location on the truck is taken while in a static position, where the truck will submerge the most.

Once the truck enters a kinematic state, the compaction will often decrease, caused by the wheels moving onto fresh snow, which is replaced repeatedly. When following the tracks of the other trucks, the snow will be compressed multiple times, which can lead to greater snow compaction. Additionally, the measured distance from the snow surface to the GPS receiver could vary in accuracy and depends largely on how frequently the
GPS position is measured. The tall and wide cluster of $\Delta H_{O I B}$ in Fig. 2A has no spatial geographical dependency but is randomly distributed over the ice sheet. Locally varying snow conditions could explain the overlapping distributions, as the uncertainty of the distance measured from the snow surface to the GPS receiver and the submergence of the wheels affect the readings. If the distance from the snow surface to the GPS is measured while on hard, sturdy snow and the vehicle later enters soft snow, the submergence gives rise to a negative error contribution. Therefore, the tall cluster could simply be a result of the local snow conditions being similar to the point where the distance from the snow surface to the receiver was measured. This would imply that the wide cluster stems from varying local snow conditions affecting the measured distance, which also explains why this cluster is much wider than the tall cluster.

The vertical accuracy of the LiDAR in the ATM instrument package is estimated to be $6.6 \mathrm{~cm}$ (Martin et al. 2012). Factoring in this uncertainty and comparing it to the $\Delta H_{O I B}$ of $10.7 \mathrm{~cm}$, it is evident that distinguishing measurement uncertainties from small elevation deviations in the snow is difficult. Also, each Operation IceBridge measurement point covers $133 \mathrm{~m} \times 45 \mathrm{~m}$, and with a worst-case nearest neighbour coverage of $283 \mathrm{~m} \times 193$ $\mathrm{m}$, using a distance of $75 \mathrm{~m}$ would certainly allow for additional errors in the range of centimetres. However, this is mitigated by weighting the neighbour distance and ATM Level 2 point compression. A larger quantity of data from Operation IceBridge across the Greenland ice sheet could lower the nearest neighbour range and possibly improve compliance between the two measuring approaches. Based on this discussion, we estimate $\varepsilon_{A T}$ to be $10.7 \mathrm{~cm}$.

Comparing the Arctic Trucks and CryoSat-2 data results in an average $\Delta H_{C S 2}$ of $92.3 \mathrm{~cm} \pm 65.7 \mathrm{~cm}$, as seen in Fig. 2B. We observed 76 large outliers outside the \pm 3 standard deviations and these were removed. The two small clusters to the right of the main distribution are both from two independent spatial geographical locations. The mean of $\Delta H_{C S 2}$ deviates by a factor of 10 compared to $\Delta H_{O I B^{\prime}}$ which is significantly larger than the estimated $\varepsilon_{A T}$ and therefore another aspect that clearly influences the result.

It has been theorised that the Ku-band of the CryoSat-2 SIRAL radar altimeter has a penetration depth of 5-12 m for dry snow snow (Nilsson et al. 2015; Remy et al. 2015). Here, we use the penetration depth to describe the height bias between the radar altimeter and the surface. Significant snow penetration was observed in 2012, when a Greenland-wide ice-melt event increased the apparent elevation of large areas of the ice sheet, with up to $2 \mathrm{~m}$ differences from June to August, which indicated that the snow penetration depth had significantly decreased. This was caused by the formation of 
refrozen melt layers, which raised the reflective surface (Nilsson et al. 2015) and scattered the SAR wave closer to the actual surface. However, this is also highly dependent on the type of processing algorithm and retracker (Sørensen et al. 2018b). Another estimate of the dry snow penetration assessed it to be $1 \mathrm{~m}$; it was a magnitude lower for wet snow (Ulaby \& Stiles 1981). The snow penetration explains the compared positive deviations, as we would expect the CryoSat-2 data to be lower than the Arctic Trucks data. There are, however, 176 crossover instances where the difference is negative. Since this large divergence only occurs with the CryoSat-2 data and without spatial correlation, we must conclude that this positive bias stems from either faulty measurements in these data or the ESA level-2 processing-chain baseline $C$. We experience similar deviations, where CryoSat-2 values are much higher than the ALS, in a study by Sørensen et al. (2018b). Using a different processing chain can limit the surface penetration of the radar (Slater et al. 2019); hence, applying a dedicated retracker could improve the coherence between Arctic Trucks and CryoSat-2, by moving the CryoSat-2 observations closer to the surface.

Despite the uncertainty in the processing chain, our analysis agrees with the results of Sørensen et al. (2018b) for the same processing chain, as the mean and median observed data are very similar for a flat area. The exact snow penetration is difficult to estimate, since temperature fluctuates significantly across the ice sheet depending on elevation, weather and latitude. Therefore, an assessment for the average snow penetration of CryoSat-2 for this April - May time period is about $90 \mathrm{~cm}$.

Finally, we investigate $\Delta H_{I R}$. The two data acquisitions are very similar in setup, except that the 2005 IceRoad traverse drove along an existing groomed snow road with fewer uncertainties, for example, no submergence. The road was slightly elevated, but this was considered when processing the IceRoad GPS data. From the $\Delta H_{I R}$ statistics (Table 1), it is apparent that a significant amount of ice has vanished from 2005 to 2018, particularly close to the edge of the ice sheet. There has been a mean loss at the edge of $17 \mathrm{~m}$ and up to $26 \mathrm{~m}$. It is evident from Fig. $2 \mathrm{C}$ that the loss is more consistent closer to the ice-sheet edge. There are also multiple instances of increased height. Further inland, the mean loss is $9.04 \mathrm{~m}$, which is similar to other estimates of the surface elevation change in this area, for example, the ESA's Climate Change Initiative (CCI) surface elevation change product (Simonsen \& Sørensen 2017; Sørensen et al. 2018a). Investigating the Arctic Trucks and IceRoad deviations from the GIMP DEM reveals an increasing difference from the Volkswagen test site toward the edge of the Greenland ice sheet. This indicates a steepening of the ice sheet moving westward, implying higher melt rates at the margins of the ice sheet than inland, which is increasingly observed across the Greenland ice sheet (Sørensen et al. 2018a).

\section{Conclusions}

Here, we have shown how opportunistic data gathered by citizen scientists can provide valuable validation data to improve satellite altimetry measurements. The data have been found to be within $10.7 \mathrm{~cm} \pm 11.7 \mathrm{~cm}$ of the traditional and more costly ALS data provided by the NASA's Operation IceBridge. This error estimate formed the basis for using the data for satellite validation. Here, coincident CryoSat-2 observations, from the ESA level-2 baseline $C$ processing chain, showed a mean snow penetration at the Ku-band of $92.3 \mathrm{~cm} \pm 65.7 \mathrm{~cm}$, which agrees with other studies applying traditional airborne ALS. Finally, the long-term durability of this opportunistic citizen science was proven by comparison to a similar truck traverse in 2005 around Kangerlussuaq. The results showed an average surface elevation change of $17 \mathrm{~m}$ and up to $26 \mathrm{~m}$ near the edge of the ice sheet. Further inland, the mean change is $9.04 \mathrm{~m}$, and we observed an increase of the slope toward the ice-sheet edge.

With a precision similar to Operation IceBridge, GPS profiles from vehicle traverses are a strong contender for collecting independent data to validate satellite and airborne height measurements, with the additional benefit option of providing other in situ data from, for example, snow pits and firn. Therefore, if geodetic GPS receivers can be supplied to opportunistic citizen scientists, we see this as a cost-efficient and valuable source of data to validate altimetry satellites. Such initiatives allow citizen scientists to compare data from one expedition to the next and see first-hand the large changes happening on the ice sheet. In this way, it could further help to engage the public and raise awareness of the large changes underway in Greenland.

\section{Acknowledgements}

We thank all contributors and participants in the American-Icelandic expedition on the Greenlandic icecap 2018 for giving us the opportunity to study the use of kinematic GPS as a validation tool. We thank Emil Grimsson, Arctic Trucks, for allowing the mount of the DTU GPS receiver on one of the expedition trucks and for the efficient installation and field operations during the traverse by the Arctic Trucks team. The operation IceBridge data were downloaded from The national snow and ice data center, and the ESA CryoSat data were downloaded from the ESA data hub. IceRoad 2005 data were collected by a DTU team of Rene Forsberg and Henriette Skourup, also on an opportunity basis, courtesy of the Nanoq snow-road maintenance team.

\section{Author contributions}

$\mathrm{RF}, \mathrm{SMH}$ and SBS conceived the idea and outlined the study. AS and SBS conceived the methodology and conducted the analysis, data processing and writing of the original draft. SMH and RF prepared the GPS equipment for the field deployment. All authors contributed to the final writing, reviewing and editing. 


\section{References}

ACS Team \& MSSL Team. 2015: CryoSat ground segment, instrument processing facility - $\mathrm{L} 2$ products format specification (L2-FMT). Baseline $C$ version. Advanced Computer Systems, Doc. No.: CS-RS-ACS-GS-5123, $98 \mathrm{pp}$. https://earth.esa.int/web/guest/missions/cryosat/ipf-baseline/-/article/cryosat-ground-segment-instrument-processing-facility-12-12-products-format-specification-12-fmt-6636

Ahlstrøm, A.P. et al. 2008: A new programme for monitoring the mass loss of the Greenland ice sheet. Geological Survey of Denmark and Greenland Bulletin 15, 61-64. https://doi.org/10.34194/geusb.v15.5045

Bouzinac, C. 2012: CryoSat Product Handbook. Report no., ESRIN ESA and Mullard Space Science Laboratory - University College London, ESA Esrin, Frascati, Italy.

Fausto, R.S., van As, D. \& PROMICE project team. 2012: Ablation observations for 2008-2011 from the programme for monitoring of the Greenland ice sheet, PROMICE. Geological Survey of Denmark and Greenland Bulletin 26, 73-76. https://doi.org/10.34194/geusb. v26.4765

Forsberg, R., Sørensen, L. \& Simonsen, S. 2017: Greenland and Antarctica ice sheet mass changes and effects on global sea level. In: Cazenave, A. et al. (eds): Integrative study of the mean sea level and its components. Space Sciences Series of ISSI 58, 91-106. https://doi. org/10.1007/978-3-319-56490-6_5

Howat, I.M., Negrete, A. \& Smith, B.E. 2014: The Greenland Ice Mapping Project (GIMP) land classification and surface elevation datasets. The Cryosphere Discussions 8(1), 453-478. https://doi.org/10.5194/tcd-8-453-2014

Khan, S.A., Aschwanden, A., Bjørk, A.A., Wahr, J., Kjeldsen, K.K. \& Kjær, K.H. 2015: Greenland ice sheet mass balance: a review. Reports on Progress in Physics 78(4), 046801. https://doi. org/10.1088/0034-4885/78/4/046801

Krabill, W., et al. 2000: Greenland ice sheet: high-elevation balance and peripheral thinning. Science 289(5478), 428-430. https://doi. org/10.1126/science.289.5478.428

Martin, C.F., Krabill, W.B., Manizade, S.S., Russell, R.L., Sonntag, J.G., Swift, R.N. \& Yungel, J.K. 2012: Airborne topographic mapper calibration procedures and accuracy assessment. Nasa Technical Memorandum, TM-2012-215891 (February). Goddard Space Flight Center Greenbelt, Maryland, USA.

Nilsson, J. et al. 2015: Greenland 2012 melt event effects on Cryosat-2 radar altimetry. Geophysical Research Letters 42(10), 3919-3926. https://doi.org/10.1002/2015g/063296

Remy, F., Flament, T., Michel, A. \& Blumstein, D. 2015: Envisat and SARAL/ AltiKa observations of the Antarctic ice sheet: a comparison between the Ku-band and Ka-band. Marine Geodesy 38(suppl. 1), 510-521. https://doi.org/10.1080/01490419.2014.985347
Seitz, B., Mavrocordatos, C., Rebhan, H., Nieke, J., Klein, U., Borde, F. \& Berruti, B. 2010: The sentinel-3 mission overview. International Geoscience and Remote Sensing Symposium (IGARSS), Honolulu, Hawaii, 25-30 July 2010, 5650772, 4208-4211. https://doi.org/10.1109/ igarss.2010.5650772

Shepherd, A., et al. 2018: Mass balance of the Antarctic ice sheet from 1992 to 2017. Nature 558, 219-222. https://doi.org/10.1038/ s41586-018-0179-y

Simonsen, S.B. \& Sørensen, L.S.L. 2017: Implications of changing scattering properties on Greenland ice sheet volume change from Cryosat-2 altimetry. Remote Sensing of Environment 190, 207-216. https://doi. org/10.1016/j.rse.2016.12.012

Skourup, H., Barletta, V.R., Einarsson, I., Forsberg, R., Haas, C., Helm, V., Hendricks, S., Hvidegaard, S.M. \& Sørensen, L.S. 2013: ESA CryoVEx 2011: airborne field campaign with ASIRAS radar, EM introduction sounder and laser scanner. DTU Space, Lyngby, Denmark, Technical Report 1, 120 pp.

Skourup, H., Einarsson, I., Forsberg, R., Haas, C., Helms, V., Hvidegaard, S.M., Nilsson, J., Olesen, A.V. \& Olesen, A.K. 2012: ESA CryoVEx 2012: Airborne field campaign with ASIRAS radar, EM introduction sounder and laser scanner. DTU Space, Lyngby, Denmark, Technical Report 2, $105 \mathrm{pp}$.

Slater, T., Shepherd, A., McMillan, M., Armitage, T.W., Otosaka, I. \& Arthern, R.J. 2019: Compensating changes in the penetration depth of pulse-limited radar altimetry over the Greenland ice sheet. IEEE Transactions on Geoscience and Remote Sensing 57(12), 9633-9642. https://doi.org/10.1109/tgrs.2019.2928232

Sørensen, L.S., Simonsen, S.B., Forsberg, R., Khvorostovsky, K., Meister, R. \& Engdahl, M.E. 2018a: 25 years of elevation changes of the Greenland Ice Sheet from ERS, Envisat, and CryoSat-2 radar altimetry. Earth and Planetary Science Letters 495, 234-241. https://doi.org/10.1016/j. epsl.2018.05.015

Sørensen, L.S., et al. 2018b: Validation of CryoSat-2 SARIn data over Austfonna ice cap using airborne laser scanner measurements. Remote Sensing 10(9), 1354, 12 pp. https://doi.org/10.3390/rs10091354

Studinger, M. 2018: IceBridge ATM L2 Icessn elevation, slope, and roughness, Version 2. 2018 data, data set ID: ILATM2. https://doi. org/10.5067/CPRXXK3F39RV

Studinger, M., Koenig, L., Martin, S. \& Sonntag, J. 2010: Operation icebridge: using instrumented aircraft to bridge the observational gap between icesat and icesat-2. International Geoscience and Remote Sensing Symposium (IGARSS), Honolulu, Hawaii, 25-30 July 2010, 5650555, 1918-1919. https://doi.org/10.1109/IGARSS.2010.5650555

Ulaby, F.T. \& Stiles, W.H. 1981: Dielectric properties of snow. pp. 91-103. Lawrence, KS: Remote Sensing Laboratory, University of Kansas Center Research Inc. 